\title{
Tähtpäevade ja pühade tähistamisest Viljandi Kultuuriakadeemias
}

\author{
Ene Lukka-Jegikjan
}

Aastaringi tähtpäevade ja pühade tähistamine on Tartu Ülikooli Viljandi Kultuuriakadeemias huvi- ja loovtegevuse juhi koolituse ja alates 2002. aastast ka kultuuriettevõtluse erialal omandatava õppeaine pärimuskultuur osa. Valitud tähtpäevade ja pühade tähistamisel on oluline nii nende varasema tähenduse ja sisu tundmine kui ka oskus neid mõtestada oma isiklikus ja tulevases tööelus tänapäeva ühiskonnas. Aluseks on veendumus, et seesugused rituaalid tuletavad meelde elutähtsaid põhiväärtusi ja annavad suurepärase võimaluse enesekorrastamiseks.

Toimuvat ette valmistades ja läbi viies lähtume traditsioonilisest rahvakalendri kombestikust, valides sealt sobiva ja improviseerimisega kohandades tänapäevaga. Rahvakalendri tähtpäevade tähistamisel ei piirduta ainult kombetalitusega, vaid erinevalt tavalistest pidudest püüame tagada korraldajate ja osalejate emotsionaalse suhte toimuvasse. Eriti oluline on kõigi sündmuses osalejate kaasamine ühistegevusse, et kohalviibijad saaksid isikliku kogemuse. Meile on heaks eeskujuks setud, kelle juures oleme käinud õppimas: Obinitsa talsipühal ${ }^{1}$ ja paabapraasnikul, ${ }^{2}$ Värska jüripäeval jms.

Tähtpäevadel ja pühadel on vanemate kursuste üliõpilased juhtivas ehk perenaiste ja peremeeste rollides. Nooremate asi on esimestel aastatel osalemine ja loodud traditsioonidega tutvumine, et järgmistel aastatel osata ise juhtida. Et vana põllunduskalender pole enam kuigi aktuaalne, on suurendatud kombestiku meelelahutuslikku ja emotsionaalset rolli.

Kui neiul või noormehel tekib isiklik suhe mõne ühiselt tähistatud tähtpäevaga, näiteks maarja- või jüripäevaga, ja ta leiab seeläbi kinnitust meheks või naiseks, tulevaseks emaks või isaks, eestlaseks, virulaseks või võrulaseks olemisele, kujuneb tal välja oskus neid pühi iseseisvalt korraldada kas oma peres, kodukandis või töökohas.

Tähistavate tähtpäevade ja pühade loend on aasta-aastalt pikenenud. Pikim traditsioon on paastumaarjapäeval, mida tähistati 2006. aastal küm- 
nendat korda, jüri- ja mardipäeva kuuendat korda. Lisandunud on ühine hingede-, kadri- ja küünlapäeva ning suvistepüha tähistamine. Aja jooksul on ühe või teise tähtpäeva läbiviimiseks välja kujunenud kindlad rituaalid, mida järeltulevate kursuste üliõpilased ei ole pidanud vajalikuks oluliselt muuta. Tähtpäeval osaleja võtab ise midagi kaasa ühisele peolauale, ohvrianniks või toob mõneks tegevuseks vajaliku eseme, nagu küünla, kadri-mardivitsa vms.

Tähistamise kohad võivad erineda, kuid ikka kaasatakse üritusele ka kohalikke inimesi. Paastumaarjapäeval Viljandis on alati Viljandi ja Viljandimaa naisi, aga vahel ka kaugemalt tulijaid. Jüripäeva on peetud Jõgevamaal Kassinurmes ning Viljandimaal Tammemäe hiiesalus, Lehola Lembitu linnuse asupaigas ja Uusna kandi imepisikeses külas. Mardisandiks on käidud põhiliselt Viljandimaal Karksi ja Viiratsi valla pisemates külades, Suure-Jaani linnakeses ning üks kord Järvamaal keset metsa asuvas Tõrvaaugu külas. Kadrisanditamise põhiline koht on Põhja-Viljandimaal asuv pisike Kuhjavere küla, kus käiakse sanditamas ka kõige kaugemates metsataludes. Hingedepäeva on peetud Viljandis, Viljandimaal Tuhalaane külas ja Pärnu linnas, suvistepüha aga Mulgimaal Uue-Suuga talus ja Kuhjavere külas. Küünlapäeva tähistamise kohaks kujuneb akadeemia asukoha tõttu ilmselt Viljandi.

Tähtpäevade ja pühade tähistamine õigel päeval ja kohases paigas on lõpetajate kaudu kandunud Eestimaa erinevatesse paikadesse. Oma osa on andnud ka Rahvakultuuri Arendus- ja Koolituskeskuses pärimuskultuuri kursustel käinud folklooriliikumise eestvedajad ja maanaiste ühenduste esindajad.

Eriti kiiresti ja loomulikult on levinud paastumaarjapäeva tänapäevane tähistamine 25. märtsil. Näiteks 2004. aastal tähistati maarjapäeva peale Viljandi veel Tallinnas Rocca al Mare Vabaõhumuuseumis, Abjas, Põlvas, Tuhala külas Harjumaal, Värskas, Tudu külas Lääne-Virumaal jm.

Nii on kaardistatud tähistatavate tähtpäevade ja pühade tähendus ning sisu tänase inimese ehk iseenda jaoks.

\section{Paastumaarjapäev}

Paastumaarjapäev, rahvasuus ka lihtsalt maarjapäev on rahvakalendri olulisimaid kevadisi tähtpäevi. Maarjapäeva kui naiste väe püha on 1990. aastatest pühitsetud asutustes ja kõrgkoolides lauludega päikest tervitades, saunas käies ja (maarja)puna maitstes (Kõiva 2004a).

Kirikukalendris märgib see aega, mil peaingel Gaabriel kuulutas Maarjale ette Jeesuslapse sündi ja seda tähistatakse üheksa kuud enne Jeesuse sündimise päeva (25. detsembrit) - seega 25. märtsil. Päev seostub Maarja kultusega (Hiiemäe 1981: 18). Päeval on teisigi nimetusi: kapsamaarjapäev ja punamaar- 
japäev. Et maarjapäev oli naistepüha, kehtisid sel päeval paljude naistetööde suhtes töökeelud. Maarjapäeva tunnuseks on olnud punajoomise tava, mille tõttu saadi kogu aastaks õitsev välimus ja puna põsile. See oli päev, mil abielunaised pidutsesid ja käisid kõrtsis. Nagu kõigil naistepühadel, nii pidid ka maarjapäeval naistepeole või selle lähedusse sattunud mehed naistele välja tegema. Vastassugupoole kimbutamine, mängud, tembud, rituaalsed tantsud jm kuuluvad kõigi naistepühade juurde. On teateid, et sel päeval riietuti valgesse, kanti valgeid rätikuid. Külla minnes tuli puna (punane mahl või vein) kaasa võtta. Päevaga seondus kevadsuvise poolaasta algus, näiteks tüdrukud lubati aita magama. Oluline oli ka kapsamaagia, sh suurte pannkookide või karaskite küpsetamine lopsakate kapsalehtede saamiseks (Kõiva 2004a).

Paastumaarjapäeva oleme tähistanud eelkõige naiste eneseteadvuse tõstmise ja endateadmise kasvatamise päevana. Teiste naistega ühtekuuluvuse tunnetamine annab elujõudu ja hea võimaluse mõtlemaks naiseks olemise peale. Väike ohvriand, mis seisneb paela riputamises raagus puule, on hea võimalus soovida õnne isiklikuks eluks, head endale ja oma lähedastele. Kombestik toetab naiste ja emade kui pärimuskultuuri kandjate rolli, väärikaks naiseks ja emaks kasvamist teiste naiste seas ning enese olemasolu tunnetamist esiemade pikas ahelas. Emaks ei sünnita ega saada lihtsalt - selleks kasvatakse vanemate ja kogenumate naiste kõrval ja nende eeskujule toetudes. Päikesetõusu ajal päikesemängu vaatamine tõstab eneseteadvust, vallandab loovuse kanalid ja annab elujõudu.

\section{Kuidas tähistatakse?}

Eelmisel õhtul küpsetatakse pannkoogid, pannakse valmis punane marja- või muu jook. Tõustakse varakult enne päikesetõusu, pannakse pähe valge rätik. Kui naine on abielus, võib ta ette siduda ka põlle.

Silmi pestakse puhta allikaveega. Kella 6 ajal minnakse mõnele kõrgemale kohale (Viljandi Lossimägedes I Kirsimäele), et tervitada päikesetõusu.

Päikesemängu jälgimine on kujunenud päeva parimaks osaks. Päikest tervitatakse esiemade loomismüütide sõnamisega, millele võib järgneda isiklik palve. Kaasa võetud lindi või paelakese sidumise ajal raagus puule võidakse taas endamisi lausuda salapalve või soov. Lintide sidumise ajal lauldakse Suure tamme laulu või muud eepilist laulu. Ühises ringis vabas õhus mängitakse ilmast hoolimata mõned laulumängud. Sellele järgneb mõnusas ruumis rituaalne pannkookide söömine, marjajoogi joomine, esiemade nimepidi nimetamine, oma nime saamise loo jutustamine, naistelaulude laulmine ja juttude jutustamine. Hästi sobivad isiklikud lood oma elust ja läbielatud sündmustest. Ka igasugused naisi, eriti vallalisi neide puudutavad ennustamised on asjakohased. 
Kui seltskonnas on Mari, Maarja, Maria, Mari-Liisu, Marju, Marje jms nimega naisi, võib pidada ka nende nimepidu.

Mõnikord on sõidetud õhtut veetma hubasesse maakodusse, kus mängitakse läbi mõni vajalik ja õpetlik rituaal, nagu lapsele nime panemine, tanutamine vms. Ühel juhul on tähistatud noore ema esimese lapse nimepäeva. Päeva lõpus võidakse minna sauna, et lugeda seal tervendavaid saunaloitse.

Viljandi Jaani kirikul ja Kultuuriakadeemia rahvamuusika õppetoolil on pikaajaline traditsioon korraldada selle päeva õhtul kirikus kontsert.

\section{Mida tunti maarjapäeva tähistamise ajal ja järel?}

- Paastumaarjapäeva tähistasin ma sel aastal teist korda ja oma kogemusest võin ütelda, et päeva omakssaamise juures on väikesi puudusi. Puudus on kas juurtest, emapiimaga saadud tunnetest või elukogemustest. Ma ootan väga aega, kui mul on lapsed, näiteks tütar, kellega koos seda päeva tähistada, või eluraskus, millest üheks päevaks välja astuda. Ma tunnen, et selles päevas on jõudu, aga ma ei oska seda omastada või siis ei vajagi. Ma ootan uut staatust ja uusi väärtusi ning energiaallikaid.

- Sellel naiste-emade pühal kutsuti mind koos meie pisikese tütre Andraga pärastlõunasele maarjapäevapeole. Varem ei osanud ma seda päeva nii sügavalt lahti mõtestada kui sel korral. Võib-olla on põhjus selles, et olen saanud endale sootuks teise - abikaasa ja noore ema - rolli. Võibolla ei peagi sellest naistele pühendatud päevast varem aru saama. Niikaua kui neiu ei ole saanud endale naise ja ema rolli, ei peagi ta ellu liiga tõsiselt suhtuma. Paastumaarjapäevast on saanud minu jaoks iseenda, oma olemuse ja elu üle järelemõtlemise aeg.

- Saime oma kohaliku maarjapäevahommiku kenasti peetud. Pärast päikese teretust käisime ohvrikivi juures. Sinna sidusime ka oma lindid. Seejärel suundusime allika juurde ja pesime värske veega nägu. Siis käisime Nõiakaevu juures, mis küll veel ei kee, aga energiasammas toimis küll. Kaasavõetud sööke-jooke nautisime taluõuel väikeses tares. Naised olid teinud erinevaid kooke-pirukaid, teesid, veingi ei puudunud, nimetasime esiemasid ja rääkisime nimede saamise lugusid ja muid mõnusaid naistejutte. Hea meel on sellest, et ka mõned vanaemad olid tulnud ja minu oma tütred polnud oma põlvkonna ainsad esindajad. Nii saime kolme põlve jutte ajada, kuigi kõige nooremad olid rohkem kuulaja rollis, aga sel viisil nopivadki nemad oma elutõed. Vaatamata nirule ilmale tuli kokku 15 naist. Meie ühise ettevõtmise tõeline väärtus oli see, et kõigile osalejaile meeldis eriti see mõte minna niimoodi varahommikul iseenda pärast päikest tervitama. 


\section{Jüripäev}

Jüripäev (23. aprill) märkis eesti rahvakalendris kevade ja kevadtööde algust. Päev on nime saanud Pühalt Jürilt. Kirikukalendri Püha Jüri on tänini oluline kunsti ja kirjanduse inspireerija, lohetapja, keda on peetud kristluse võidu sümboliks paganluse üle (Kõiva 2004b). Eestisse on Püha Jüri kultus tulnud nii läänest kui idast. Jüripäeva tähtsus majanduslikus ja ühiskondlikus elus hakkas välja kujunema 13. sajandil, kui maa alistasid ristirüütlid.

Kuna jüripäev oli sobiv kevadtööde alguseks, määrati see ühtlasi teotöö alguse, rendimaksmise, elukohamuutuse ja teenistuslepingute jõustumise päevaks. Nii kujunes jüripäev majandusaasta alguseks ja sellele päevale kandusid nii esimene karjalask kui ka põllutööde alustamine (Hiiemäe 1984: 9). Tänapäeval on jüripäev koristuspäev, skautide ja gaidide suurlaagri päev (Püha Jüri, õilis rüütel, on skautluse kaitsepühak, skaudid aga tänapäeva rüütlid igal aastal korraldavad nad jüripäevaürituse mõnes uues Eestimaa paigas, et õppida kodumaad tundma). Paljudes kohtades on see jüripäevajooksu aeg, mida algatavad koolid ja spordiseltsid, Tartus aga näiteks Eesti Rahva Muuseumi Sõprade Selts (Kõiva 2004b).

Jüripäeva ühised rituaalid kindlustavad põllumehe tööde kordaminekut ja ühine lõbutsemine annab hoogu ja jõudu raskeks tööks. Kultuuriakadeemia jüripäevakombestikus on olulisel kohal ka Jüriöö ülestõusu (1343) aastapäeva tähistamine, oma maa ja vabaduse eest võidelnud sõjameeste mälestamine tule ääres. Tähelepanu keskmes on mees kui oma kodu ja maa kaitsja. Eestlusest ja vabadusest kõnelemine ning selle väärtustamine on

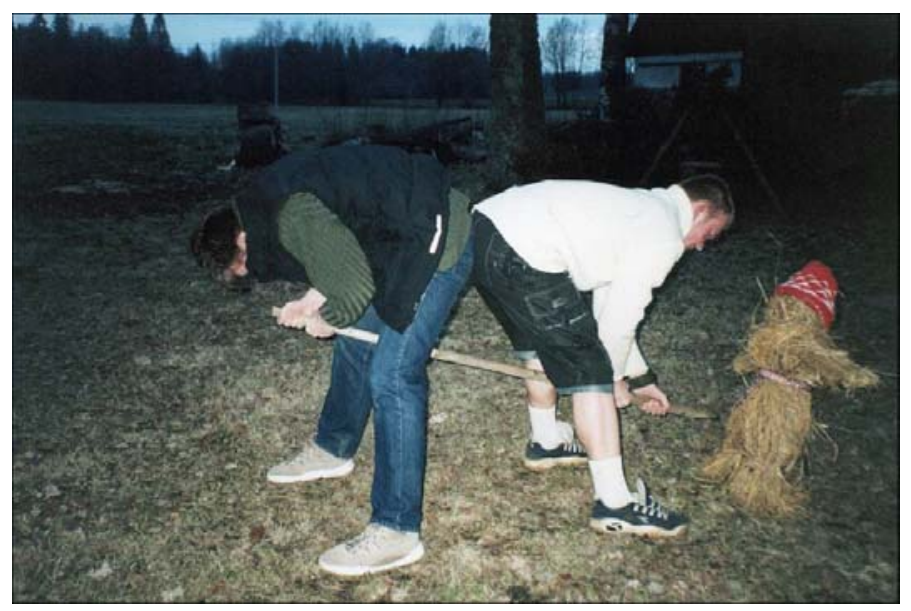

Foto 1. Jüripäeva rahvamängud Viljandimaal Tammemäe hiiesalus 2001. aastal. Ene Lukka-Jegikjani foto. 
hea võimalus poegade kasvatamiseks. Rituaalid tule ümber annavad võimaluse vabaneda kõigest halvast, puhastavad ja tekitavad usu paremasse tulevikku, aga vabastavad inimesi ka võimalikust stressist.

\section{Kuidas tähistatakse?}

Kaasavõetud söögipoolis asetatakse kivile või lauale. Sissejuhatava päevakohase kõne peab üks selle päeva peremehi. Jürituli süüdatakse ühise tuleloitsuga, mille teksti on loonud üliõpilased ise.

Ühises mälestusringis võidakse nimetada sõdades hukkunud suguvõsa liikmeid, jutustada mõni nendega seonduv lugu või laulda laul. Seda on tehtud näiteks ühe Vabadussõja veterani mõõka edasi andes või lihtsalt niisama.

Tulele ohverdatakse midagi mõne esivanema mälestuseks või mõnest halvast asjast lahtisaamiseks. Tule ümber lauldakse vanu sõja-, nekruti- ja sõdurilaule.

Puu (tamme või pihlaka) istutamine Suure tamme laulu ja puuteemaliste lugude saatel on saanud samuti heaks traditsiooniks. Istutatud puu juures loetakse eepost Kalevipoeg.

Ühist tähtpäevajooki (kali, mahl) juuakse ringis seda käest-kätte andes. Kaasavõetud toidupoolise söömisele on järgnenud rahvamängud. Jüripäev lõpeb iidse Venna sõjaloo laulmisega.

\section{Mida tunti jüripäeva tähistamise ajal ja järel?}

- See, et igaüks rääkis loo oma vanaisast või mõnest muust kangelasest suguvõsas, tõi mulle endale meelde väga palju mälestusi seoses oma vanaisaga ja see tegi meele natuke kurvaks.

Aga puude istutamine oli minu jaoks selle päeva parim hetk... Seda tahaksin ka tulevikus ise teha...

- Jüripäev on minu jaoks üks kevade verstaposte. Kui võrrelda jüripäeva ja jüriöö tähendust, siis minu jaoks on tähtsam jüriöö. See ajalukku jäänud öö, kui toimus talurahva ülestõus. Ö̈̈, millal tuhanded eestlased sü̈̈tasid lõkkeid ja mõisaid, et vabaneda baltisakslaste ikke alt.

- Minu jaoks oli enne ja on ka praegu see päev kuidagi minevikku vaatamise päev, aga ka kuidagi tõeliselt nukker päev. Hea on meenutada oma esiisasid ja mõelda nende elu peale. Samas jääb kurb tunne, et neid enam ei ole ja sa ise neile öelda ei saa, mida sa nüüd teistele räägid. Ma ei ole eriline meenutaja, seepärast on see päev võib-olla üks ainsamaid aastas, kui ma võtan kätte ja meenutan või olen sunnitud meenutama. Ja see on hea, sest pärast meenutust valdab mingi emot- 
sioon, olgu see siis kurb või rõõmus. Sellest päevast ei saa ilmselt kellelegi päris tühi tunne jääda. Mulle tundus, et kohalikud inimesed, kes meiega ühinesid, tundsid, et neil on samuti seda päeva vaja enese ja mineviku meenutuste jaoks.

- Jüripäev on vajalik meie elukorralduses, sest kõigil on aina enam ja enam kiire kuskile, vahel tekib tunne, et miks joosta, inimesed ei tea oma sihtmärkegi enam. Need muutuvad nii kiirelt kui kuupäev kalendris. Kuid just siis ongi vaja sõita ära kuskile metsade ja põldude vahele, teha üks pisike tuli ja mõelda sellele, mis on tähtis - mõelda sellele, millest on läbi käinud esivanemad ja kui nad on veel olemas, siis neile küllagi minna.

\section{Suvisted}

Nelipühad ehk suvisted (suviste-, suve-, suipühad) on sisuliselt suve vastuvõtmise pühad ning jäänud kirikuga üsna nõrgalt seotuks. Liikuva pühana langevad suvisted ajavahemikku 10. maist 14. juunini. Kristlike nelipühade taustaks on muistsete heebrealaste lõikuspüha, mida tähistatakse seitse nädalat pärast lõikuse algust. Suvistete kombestiku seos põllunduskalendriga on jäänud kaudseks. Põhirõhk on noorte koosviibimistel, lembetunnete avaldamisel ja meelelahutusel (Hiiemäe 1984: 209).

Rahvakalendris on suvisted olnud oluline peo- ja naljapäev, kindlasti meeldejäävamaid aasta pühi kaselõhna ja rõõmsa meeleolu tõttu. Metsast toodi kased, millega ehiti maja, laut, kiik ja noorte kogunemispaik. Varem toodi tuppa noori kaski ja pandi toanurka vette seisma, tänapäeval piirdutakse tihti okstega. 19. sajandi ja 20. sajandi alguse külatava kohaselt käisid noormehed kaskede järel ja muu hulgas jätsid meiud värava taha tütarlapsele, kes neile meeldis. Kuid kaskedel on käinud järel ka oma pere noored või isa/vanaisa lastega, nii nagu on ühiselt toodud metsast jõulukuuske. Kased kaunistasid ka tantsu- ja kiigeplatsi, samuti viidi kased nelipühaks kirikusse. Tuppa toodi veel õitsvaid toomingaoksi, kullerkuppe, pääsusilmi, angervaksu ja muid lilli (Kõiva 2004c).

Suvisted on noorte püha, rõõm noorena looduses olemisest, ootusrõõm millegi uue ja ärkava - taassündiva looduse - ees. Kaskede toomine metsast ja päikese jälgimine rikastavad tundemaailma, tekitavad erilise kokkukuulumistunde kogu ümbritseva maa ja ilmaga ning toovad looduse inimesele taas lähemale. See on hea võimalus kogu looduskeskkonna väärtustamiseks ja just nendest tunnetest lähtub ka Viljandi Kultuuriakadeemia oma suvistete tähistamisel. 


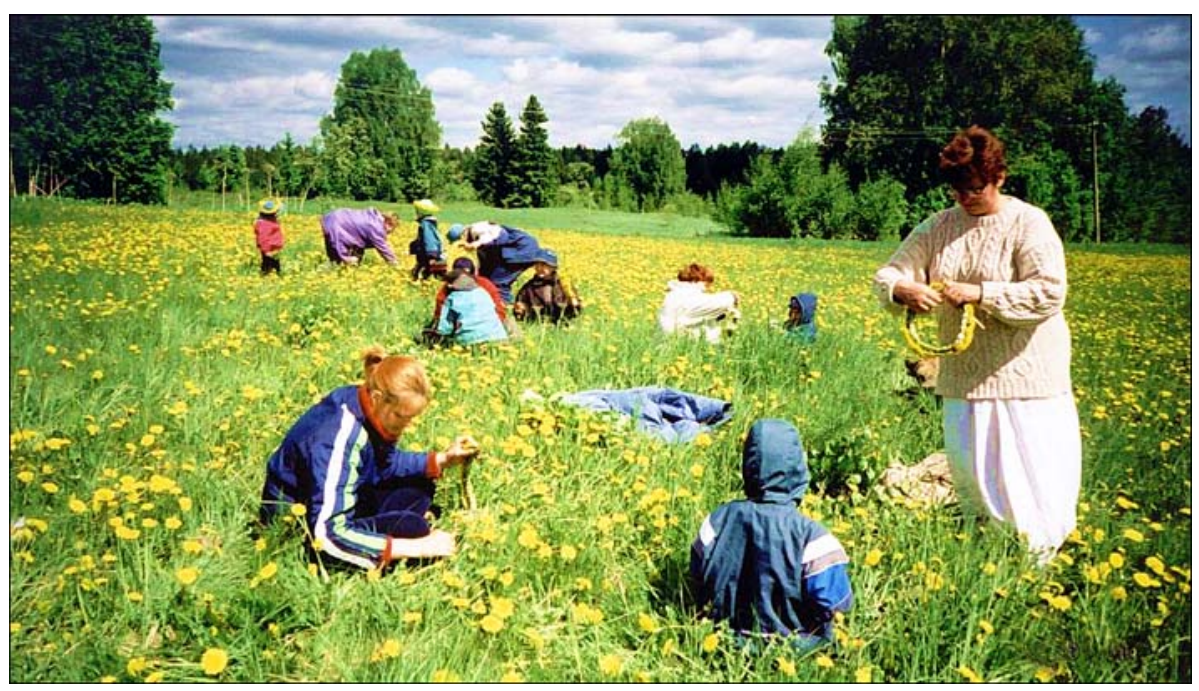

Foto 2. Suvistepüha 2002. Lillevanikute valmistamine. Ene Lukka-Jegikjani foto.

\section{Kuidas tähistame?}

Kokkuleppel kohaliku rahvaga käiakse ühiselt metsas kaski toomas ja saunavihtu tegemas. Kui on mõni kohalik taimetundja, tutvustab ta sealkandis kasvavaid ravimtaimi, mida ka kaasa korjatakse. Ühiselt käiakse mõnes erilise loodusega paigas, nagu rabas või unustuse hõlma vajunud karjatanumal jms. Leitakse aega lihtsalt looduses olemiseks. Vastastikune laulmine, rahva- ja laulumängud sobivad nii metsa, põllule kui ka külaplatsile. Tähtsal kohal on sel päeval kiikumine ja kiigelaulud. Kuhjavere külas näiteks korraldati külakiige parandamise talgud.

\section{Hingedeaeg ja hingedepäev}

Katoliiklikus kirikukalendris kehtestati 1006. aastal 2. november hingedepäeva ehk usklike surnute mälestuspäevana. Eestlastel jääb hingedepäev hingedeaja sisse. Hingedepäeva on nimetatud juba 14. sajandi allikates, kuid tema tähistamine (nagu ka 1. november ehk pühakutepäev) on jäänud omauskumustele tugineva hingedeaja varju. 1990. aastatel levis tava süüdata hingedepäeval koduakendel ja kalmistul sugulaste haudadel lahkunute mälestuseks küünlad (Kõiva 2004d). Muistsel hingedeajal kehtis nii vaikusenõue kui tööde keeld. Keelatud tööde hulgas olid just õhtused tubased tööd, nagu ketramine, õmblemine või kraasimine, sest esivanemate hingi usuti saabuvat õhtusel ajal. On pärimusteateid hingede söötmisest ja vastuvõtust (Hiiemäe 1991: 234). 
Hingedeaeg ja hingedepäev on vaikuse, rahu ja mälestuste aeg. Selle pühitsemisega on seotud oma juurte tunnetamine, esivanemate ja sugulaste mälestuse pühitsemine, austus surnud esivanemate vastu ja lepituse otsimine kõige ja kõigiga, aga ka enda ja eemalolevate lähedaste peale mõtlemine. Viljandi Kultuuriakadeemiaski lähtutakse selle päeva tähistamisel põhimõttest, et mõtetes ollakse koos nii elavate kui ka surnud lähedastega ja võetakse nendega kontakti. Võetakse aeg maha, mõeldakse oma suhetest surmaga ja vaadatakse endasse.

\section{Kuidas tähistatakse?}

Tähistades hingedepäeva koos konkreetse küla- või linnarahvaga, peetakse sel päeval meeles lisaks oma suguvõsa lähedastele veel kohalikke kultuuritegelasi jt tähtsaid isikuid, nimetades neid nimepidi, meenutades nende tegusid ja juhtumeid nende elust. Mälestusteringis osalevad kõik kohalviibijad.

Tuli on kesksel kohal nii ühises söögilauas, teekonnal kohalikku surnuaeda kui ka surnuaias. Surnuaias lauldakse rahvalaule või rahvalikke üldtuntud laule emast, kodust jms.

Hingesandid käivad ukse taga ulumas ja toas toitu nurumas. Iga üliõpilane kirjutab essee teemal Hingedepäeval on minu lähedased minuga.

- Miks tekib kõige suurem läheduse vajadus just hingedeajal? On külm, kôle ja niiske sügis, ees ootab talv. Otsitakse tuge hetkel kaugele jäänud perekonnalt, armsamalt, sest üksi on seda pimedat aega raske üle elada.

Kõikjal säravad akendel tuled. Elav tuli on soojuse ja puhastuse sümbol. See peletab eemale kõik halva, luues samas tuppa õdusa õhkkonna. Elus tuli tekitab sellise tunde, et sa ei viibi ruumis üksi. Kü̈̈nal aknal on teenäitajaks kõigile, kes on meie hulgast lahkunud. Kui nad sealt teiselt poolt meie poole vaatavad, näevad nad tuld, mis on sü̈̈datud neile ning selle paistel kohtuvad nad meiega...

- Meie perel on komme hingedepäeva õhtul alati surnuaeda minna, et seal kü̈̈nlad sü̈̈data. Käia on vaja kahes surnuaias: üks on kodule lähemal ning seal saab tihemini käidud. Teine on suhteliselt kaugel, Peipsi ääres, kus me igal aastal koos perega siiski vähemalt kaks korda käia pü̈̈ame. Sinna on maetud mu isapoolsed vanavanemad, kellega ma kunagi kohtunud pole ning kellest ma kahjuks väga vähe tean. Ometigi on just see Peipsi-äärne väike küla oma vana surnuaiaga koht, kuhu tee alati viib, kui hinges on tühjus. Hingedepäeval võimendub see tunne veel mitmekordseks, kuid surnuaiast ei lahku kunagi tühjusetundega hinges. 
- Hingedeaeg on aeg enda jaoks. Kõigele sellele annavad aga mõtte inimesed meie ümber, eelkõige perekond ja lähedased sõbrad, kelle olemasolu ja tähtsust igapäevaste kiirete toimetuste keskel unustama kiputakse.

See püha külmal ja pimedal aastaajal peaks meid ometigi täitma lootusega. Ning isegi kui me hingedepäeval üksi oleme, on meie lähedased meiega meie mõtetes.

- Selleaastane hingedepäev oli mul plaan viia kü̈̈nal õues olevale koera hauale. Kuid mul ei olnud sellist kü̈̈nalt, mis oleks kuskil topsi sees olnud ning seetõttu olin sunnitud toas kü̈̈nla sü̈̈tama, mis ei olnud ka halb mõte. Sü̈̈tasin oma kü̈̈nla koerale, kes jäi eelmisel talvel auto alla.

\section{Mardi- ja kadripäev}

Mardipäev (10. november) on tänini elav rahvakalendri tähtpäev. Eeskätt teame seda mardisantide ehk martide ringijooksmise tõttu. Veel 20. sajandi alguses jooksid marti pigem noormehed ja seetõttu on püha seostatud näiteks noorte meeste initsiatsiooniga ehk vastuvõtuga meeste kogukonda. Tüüpilised olid tumedasse riietatud mardid, kelle tulek tõi kaasa viljaõnne. Varem on see olnud päev, mil tuli mõistatada ja mida peeti hingedeajaga kokkukuuluvaks - hinged tulid koju, mardipäev lõpetas hingedeaja. Pika traditsioonis püsimise jooksul on mardikombestik palju muutunud ja sulatanud endasse mitmeid uusi jooni (Kõiva 2004e).

Santima läheb mardiperekond, kus peamees on meesterahvas, mardiisa. Mardiema pole kuigi oluline. Vahel lepitakse kokku, et mardiisa ajab juttu ja mardiema kaelas on andidekott. Niisuguses seltskonnas liigub veel mitmesuguseid tegelasi, kes nagu ei kuulukski perekonda. Vanasti oli kõige tavalisem mardisandirõivas väljapoole karvane talvejope ja läkiläki, naistel ka pearätt. Nägu tõmmati söega mustaks. Tänapäevaks on maskeerimisvahendite valik tänu grimmile ja meigile suurenenud (Hiiemäe 1999: 7).

Kadripäev (25. november) on eestlastel vana ja rikkaliku kombestikuga tähtpäev, mis tagas karjaõnne. Juba sada aastat on see aga ennekõike kadride ehk kadrisantide jooksmise aeg, kui maskeeritakse ja kogutakse ande. Laulud ja kogu kadrirituaal sarnaneb mardipäeva omaga, samuti õnnistamissõnad ja manamised, mida kadrid pererahvale lausuvad. Siiski on neiski tavades toimunud mitmeid muutusi. Näiteks palusid 19. sajandi kadrid rohkem villu jm näputööks vajalikku, vähem toiduaineid. Mida edasi, seda olulisemad olid kommid ja maiustused ning muidugi ka raha. Juba nimetusest selgub, et ringi rändasid 
ennekõike naised või naisteks riietunud, maskide valikus on aja jooksul toimunud suuri muutusi (Kõiva 2004f). Kadrisantide eesotsas on tavaliselt kadriema. Perekondlikku kuuluvust rõhutavad kadrid isegi rohkem kui mardid. Noorpaarideks rõivastutakse sagedamini kui mardikskäimisel. Kadridel, kes enamasti naisterahvaks maskeeruvad, võib kaasas olla kadrititt. Vastandina martidele seadsid kadrid end uhkeks ja ilusaks. Seljas kanti voodilinu ja kardinaid, millele lisati rohkesti kaunistusi. Peakattena kanti laia äärega kübaraid ja kaabusid (Hiiemäe 1999: 8-9).

Tänapäeval kuulub mardi- ja kadripäevane sanditamine eelkõige lastetraditsiooni, sageli on vanad mardi-ja kadrilaulud asendunud juhusliku repertuaariga. Seega on vana traditsiooni õpetamine ja meeldetuletami-

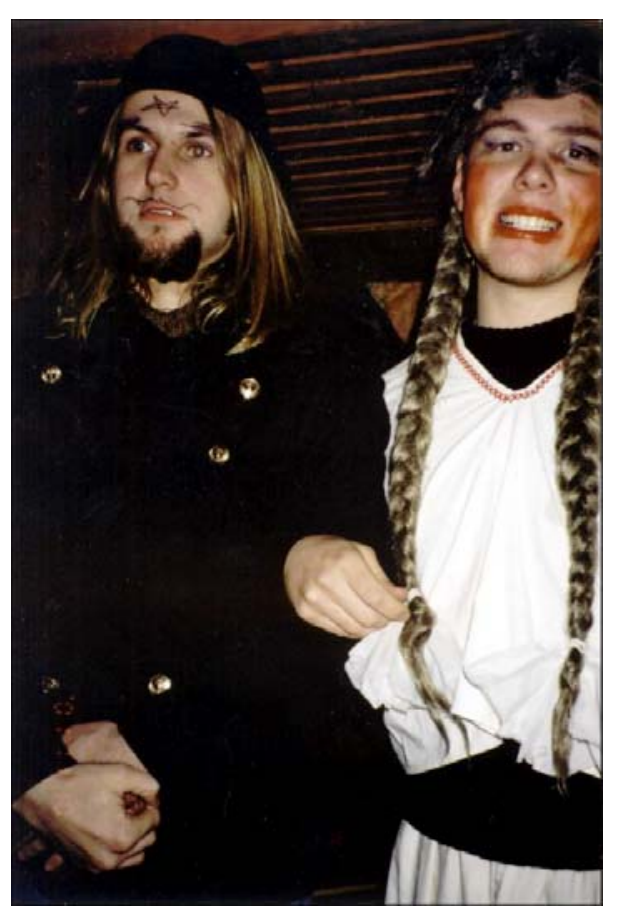

Foto 3. Mardipäev Tõrvaaugus 2001. Mardipulma pruutpaar. Ene Lukka-Jegikjani foto. ne üsna vajalik. Kunagised sanditamisele järgnenud mardi- ja kadripulmad on asendunud koolides ja lasteaedades korraldatavate karnevalidega.

Mardi- ja kadripäev aitavad hoida sidet esivanemate (pere- ja hõimutunne) ja paikkonnaga (kohalik identiteet). Need päevad annavad suurepärase võimaluse emotsionaalse ja kultuurilise kontakti loomiseks teiste omakandi inimeste ja omakultuuriga. Oluline on ühine ettevalmistamine.

Mardisandiks või kadrisandiks maskeeritakse ka ajutise identiteedi muutmise vajadusest - vajadusest üks kordki aastas vabaneda oma rollist ja olla keegi teine. See on omamoodi eneseületamine nii lastele kui ka täiskasvanutele. Oluline koht on ka traditsioonilisel viljakuse ja saagikuse pühitsemisel ning onnne toomisel kodudesse. Sanditamisega kaasnevast andmiserõõmust või valmisolekust heategevuseks - mida ja kui palju santidele antakse või kas neid üldse sisse lastakse - saadakse samuti ülevaade.

\section{Kuidas tähistatakse?}

Kuna sandiks käiakse võõras kandis, on igas rühmas kohalik teejuht. Sel viisil käiakse läbi kaugeimadki talud ja majad. Kaasates pererahvast, mängitakse 
läbi kogu mardi- või kadririituste tsükkel mardiisa või kadriema eestvedamisel. Riituste osi veavad erinevad osalised ja rollid on omavahel jaotatud.

Mardipäev lõpetatakse kõigi santide osalusel hoogsa mardipulmaga, milles väiksematesse rollidesse haaratakse ka kohalikud. Mardipulma aluseks on eesti traditsioonilised pulmakombed ja -tavad. Tähtsamad pulmategelased on isamees, pruutpaar, pruuttüdrukud, peiupoisid, preester, pruutpaari vanemad, pulmatola, pulmalaulikud ja -pillimees.

Kadripäev lõpeb ühise kadripeoga kohalikus külamajas või mõnes suuremas talus.

\section{Mida tunti mardipäeva tähistamise ajal ja järel?}

- Sanditamine Suure-Jaani linnakeses oli põnev ning see aitas meelde tuletada neid tundmusi ja meeleolusid, mis valdasid meid väikeste koolijütsidena - siis, kui käisime järjepidevalt igal aastal marti jooksmas. Väga halb tunne jäi siis, kui pika laulmise järel meid maja või korteri uksest sisse ei lastud ning kurvalt edasi sammuma pidime. Kohalikud lapsed olid sanditamiseks hästi valmistunud, eriti põnevad olid neil kostü̈mid (mille kallal nad olid palju vaeva näinud). Pärast rolli sisemist omaksvõtmist tundsime end hästi. Selleks, et sandi rolli omaks võtta, tuli ületada mingi barjäär. Arvame, et selle barjääri ületasime esimeses kodus, kuhu meid sisse lasti. Pärast rolli omaksvõttu kadus totter valehäbi ning omaksvõetud roll tundus meeldiv ja mõnus. Huvitav oli jälgida, kuidas kohalik rahvas elab, ning mõistatada, millega nad oma argielus tegeleda võiksid. Tundus, et meiega kaasas olevad lapsed tundsid end oma rollides vabamalt ega pidanud selleks erilisi barjääre ületama. Arvame, et kultuuriakadeemia sandid olid asjatundlikud, julged ning heasoovlikud - tõelised sandid, kelle eesmärgiks polnud üksnes kommikotid.

\section{Kokkuvõte}

Viljandi Kultuuriakadeemia lähtub rahvakalendri tähtpäevade tähistamisel vanast traditsioonist, kuid rõhutab ja süvendab eelkõige selle emotsionaalset mõõdet. Et rahvakalendri tähtpäevad on oma rolli põllunduskalendri verstapostidena kaotanud, on esiplaanile nihkunud nende meelelahutuslik funktsioon. Ka selleks on esivanemate pärandis eeskujud olemas, kuid paraku on praegune, linnalik eluviis koos meediapõhise maailmapildiga jätnud unustusehõlma hulga algupärast pühaderepertuaari. 
Viljandi Kultuuriakadeemias õpetatava pärimuskultuuri nime kandva õppeaine eesmärk ongi juhatada õppurid, hiljem nende tegevuse kaudu ka kohapealne rahvas emotsionaalse kogemuse kaudu tagasi rahvapärimuse juurde.

\section{Kommentaarid}

${ }^{1}$ Talviste või taliste või talsipüha on vana lõunaeesti sõna, millega märgitakse jõuluaega. Sellel on selge etümoloogia - need on vastandina suvistele talvise aja pühad (Salve 1998). Setu talsipühad on mõjustatud õigeusu jõulunädalast ( $c b s m$ $k u)$.

${ }^{2}$ Paabapraasnik, paabapäev on Setus suure paastu keskmise nädala neljapäeval tähistatav naistepüha ja selle kombestik on seotud laiskusest hoidumisega (Lätt 1970: 161).

\section{Kirjandus}

Hiiemäe, Mall (koost) 1981. Eesti rahvakalender 2: Rahvapärimusi alates kevadisest pööripäevast ja lõpetades lihavõttepühadega. Tallinn: Eesti Raamat.

Hiiemäe, Mall (koost) 1984. Eesti rahvakalender 3: Jüripäevast viidipäevani. Tallinn: Eesti Raamat.

Hiiemäe, Mall (koost) 1991. Eesti rahvakalender 5: rahvakombeid ja -uskumusi. Tallinn: Eesti Raamat.

Hiiemäe, Mall 1999. Mardipäev ja kadripäev. Tallinn: Olion.

Kõiva, Mare 2004a. Maarjapäev, ka paastumaarjapäev, punamaarjapäev, kapsamaarjapäev - 25. märts. Kõiva, Mare \& Särg, Taive \& Vesik, Liisa (koost). BERTA: Eesti rahvakalendri tähtpäevade andmebaas (http://www.folklore.ee/Berta/tahtpaev-maarjapaev.php - 4. oktoober 2006).

Kõiva, Mare 2004b. Jüripäev - 23. aprill. Kõiva, Mare \& Särg, Taive \& Vesik, Liisa (koost). BERTA: Eesti rahvakalendri tähtpäevade andmebaas (http://www.folklore.ee/ Berta/tahtpaev-juripaev.php - 4. oktoober 2006).

Kõiva, Mare 2004c. Nelipühad (suvistepühad, kasepühad) - liikuvad pühad, seitsmes pühapäev pärast lihavõtteid, 10. mai ... 14. juuni. Kõiva, Mare \& Särg, Taive \& Vesik, Liisa(koost). BERTA: Eesti rahvakalendri tähtpäevade andmebaas (http://www.folklore. ee/Berta/tahtpaev-nelipuhad.php - 4. oktoober 2006).

Kõiva, Mare 2004d. Hingedepäev - 2. november. Kõiva, Mare \& Särg, Taive \& Vesik, Liisa (koost). BERTA: Eesti rahvakalendri tähtpäevade andmebaas (http://www.folklore. ee/Berta/tahtpaev-hingedepaev.php - 4. oktoober 2006).

Kõiva, Mare 2004e. Mardipäev - 10. november. Kõiva, Mare \& Särg, Taive \& Vesik, Liisa (koost). BERTA: Eesti rahvakalendri tähtpäevade andmebaas (http://www.folklore. ee/Berta/tahtpaev-mardipaev.php - 4. oktoober 2006). 
Kõiva, Mare 2004f. Kadripäev - 25. november. Kõiva, Mare \& Särg, Taive \& Vesik, Liisa (koost). BERTA: Eesti rahvakalendri tähtpäevade andmebaas (http://www. folklore.ee/Berta/tahtpaev-kadripaev.php - 4. oktoober 2006).

Lätt, Selma 1970. Eesti rahvakalender I. Tallinn: Eesti Raamat.

Salve, Kristi 1998. Mõned armsad vanad jutud jõuludeks noortele ja vanadele lugeda. Mäetagused: Hüperajakiri 6, lk 123-128 (http://www.folklore.ee/Tagused/nr6/joulu1. htm - 4. oktoober 2006).

\title{
Summary
}

\section{Celebration of Holidays and Festivities at the Viljandi Culture Academy}

\author{
Ene Lukka-Yegikian
}

The celebration of yearly festivities and holidays has been one of the most important foci of the subject of lore culture offered to the students studying to become creativity and hobby managers and since 2002 also to students studying culture management at the Viljandi Culture Academy of the University of Tartu.

The important aspects of celebrating certain holidays and festivities are being knowledgeable of the former meaning and contents as well as the ability to conceptualise these in personal and future professional life in contemporary postmodern society. The idea is based on the conviction that holiday and festive rituals help to remember the basic values of life and provide an excellent opportunity to organise ourselves. Making preparations for and carrying out a ceremony is based on rich folk calendar tradition. Choosing an appropriate event prompts a constant improvisation in tradition.

For acquiring personal experience, it is important that all participants at an event are asked to join in on the activities. We have learned a great deal from participating in the celebrations of the Setu - the talsipüha or yuletide, and the women's feast paabapraasnik in Obinitsa, St. George's Day in Värska, etc.

On these festivities and holidays, senior year students act in leading roles as farmers and their wives. In the first years, younger students take part in the events and get acquainted with the established tradition to learn the leading roles for the years to come.

The list of celebrated festivities and holidays has expanded over the years. Celebrating Lady Day has the longest history, as in 2005 it will be celebrated for the 9th time; also, St. George's Day and Martinmas is celebrated for the 5th time. In recent years the collective celebration of All Souls' Day, St. Catherine's Day, küünlapäev (lit. Candle Day) on February 2, and Whitsuntide have been added. Over the years, specific rituals and activities have been developed for organising a certain celebration that students of the following years have not considered necessary to change. 